\title{
Microstructural evolutions and mechanical properties of drawn medium carbon steel wire
}

\author{
MC.NEBBAR ${ }^{1,2}$, M.ZIDANI $^{1}$, T.DJIMAOUI ${ }^{1}, H$. FARH $^{3}$, T.ZIAR $^{3}$, T.ABID $^{4}$, \\ A.L. HELBERT ${ }^{5}$, F. BRISSET ${ }^{5}$, T.BAUDIN ${ }^{5}$
}

\author{
${ }^{1}$ Université Mohamed Khider Biskra, Laboratoire de Génie Energétique et Matériaux \\ (LGEM), Faculté des Sciences et de la Technologie, Biskra 07000, Algérie. \\ 2 Centre de Recherche Scientifique et Technique en Analyses Physico-chimiques (CRAPC)- \\ BP 384, Bou-Ismail, RP 42004, Tipaza, Algérie. \\ ${ }^{3}$ Laboratoire des composants actif et matériaux, Oum el Bouaghi, Algeria \\ ${ }^{4}$ Tréfisoud - ZI, BP. 09 El Eulma - Sétif-Algérie. \\ ${ }^{5}$ ICMMO, SP2M, Univ. Paris-Sud, Université Paris-Saclay, UMR CNRS 8182, bât.410, \\ 91405 ORSAY, France.
}

Keywords: Medium carbon steel, Wire rod, Wire drawing, Spring mattress, Texture.

\begin{abstract}
This study focuses on the evolution in the microstructure, texture and mechanical properties of medium carbon steel wires obtained by wire drawing at Tréfissoud Company for the manufacturing of the spring mattress. Wire drawing induces elongation of grains in the direction of drawing with the development of the $\langle 110\rangle$ fibre texture parallel to the wire axis. Kinking and bending of cementite lamellae were observed during the drawing process. The work was carried out respectively on three states, wire rod and drawn states for two different amounts ( $\varepsilon \%=43,6$ and $60 \%)$, using the optical and SEM microscopy, electron backscatter diffraction and $X$-ray diffraction analysis for examination of the microstructure and texture evolution, the hardness Vickers and tensile test to follow the curing of the studied wires.
\end{abstract}

\section{Introduction}

Wire drawing is a forming process used to reduce the diameter of a wire by pulling the wire through a single or series of drawing dies. During this forming process, the material microstructure changes which obviously affect its mechanical properties and consequently the product resulting from the process [1]. Cold drawn steel wires have been widely used for a variety of applications, such as cables for suspension bridges, steel cords for tires reinforcement, and springs [2,3]. The medium steel wires cold drawn are frequently used in the manufacturing of the bonnell springs intended for mattress. The progressive anisotropy of the crystallographic texture or the grains elongation (morphological texture) induced in the material by cold drawing as a consequence of the important changes at the microstructural level. Thus, although it is clear that cold drawing improves the mechanical properties of the steel, the microstructural changes during manufacture may produce anisotropy $[4,5]$. Embury and Fisher [6]and Li et al [7]studied the microstructure of a pearlitic steel during wire drawing 
and described the formation and the development of the fibrous structure and a texture of fibre $<110>/$ WA (where WA is the wire axis).

In this work, cold drawing ferritic-pearlitic wires for producing springs, were studied in longitudinal section to follow the evolutions of the microstructure, crystallographic texture and mechanical properties and to have the correlation between microstructural and mechanical properties of C68D medium carbon steel wires.

\section{Experimental Procedures}

\subsection{Materials}

The present study was carried out on medium carbon steel wires provided by TREFISSOUD JSC., Algeria. The chemical composition of steel is listed in Table 1.

Table 1- Chemical composition of medium carbon steel C68D (wt \%)

\begin{tabular}{cccccccc}
\hline $\mathbf{C}$ & $\mathbf{M n}$ & $\mathbf{S i}$ & $\mathbf{P}$ & $\mathbf{S}$ & $\mathbf{C r}$ & $\mathbf{N i}$ & $\mathbf{C u}$ \\
\hline 0.675 & 0.649 & 0.18 & 0.008 & 0.017 & 0.051 & 0.036 & 0.048 \\
\hline
\end{tabular}

To the microstructural observations, all the samples were subjected to mechanical polishing performed on SiC abrasive papers of different grain sizes (P100, P180, P240, P400, P600, P800, P1000, P1200, P2400 and P4000) with oil-based diamond. After the mechanical polishing, the samples were chemically etched with Nital 3\% (3 ml of nitric acid with $97 \mathrm{ml}$ of ethanol) to reveal microstructure.

To analyses the crystallographic texture, the samples are polished with granulometry papers (1200, 2000 and 4000) followed by diamond polishing (3 $\mu \mathrm{m}$ and $1 \mu \mathrm{m})$ and then electro-polishing to remove the mechanical polishing layer.

\subsection{Characterization technics}

The microstructure and texture evolution in medium carbon steel wires were characterized by scanning electron microscopy FEI quanta 250, TSL EDAX electron backscatter diffraction in the scanning electron microscopy Zeiss 940 equipped with OIM $^{\mathrm{TM}}$ software and $\mathrm{x}$-ray diffractometer Bruker D8 Advance. The Vickers hardness measurement was carried out by applying $500 \mathrm{~g}$ load. The tensile strength and elongation were determined by tensile tests performed on wires samples of $30 \mathrm{~cm}$ of length with Zwickroell Z250 tensile testing machine.

\section{Results and discussion}

\subsection{Evolution of microstructure}

Microstructures of drawn wires (wire rod anddeformed wires) were examined over the longitudinal wire section. Figures $1(\mathrm{a}-\mathrm{c})$ show the microstructures of the wires with various deformation levels. The microstructure of steel wire rod (Fig.1-a) shows an irregular distribution (isotropy) of the colonies of pearlite. Four forms of cementite lamellae are observed during wire drawing (Fig.1-b) which are the bended, kinked, thinned and aligned cementite lamellae along wire axis. As a result of development of fiber texture $\langle 110\rangle$ in the wire axis direction $[8,9]$. 
The figure 1(c) shows that under the wire drawing process most pearlite colonies and ferrite rotated to the drawing direction.

A schematic description of lamellae deformation is proposed in Figure 2. The cementite lamellae that are oriented in the direction of the wire axis have been thinned (Fig.2 a), and the lamellae that are randomly oriented try to orient in the direction of the wire axis (Fig.2 b).

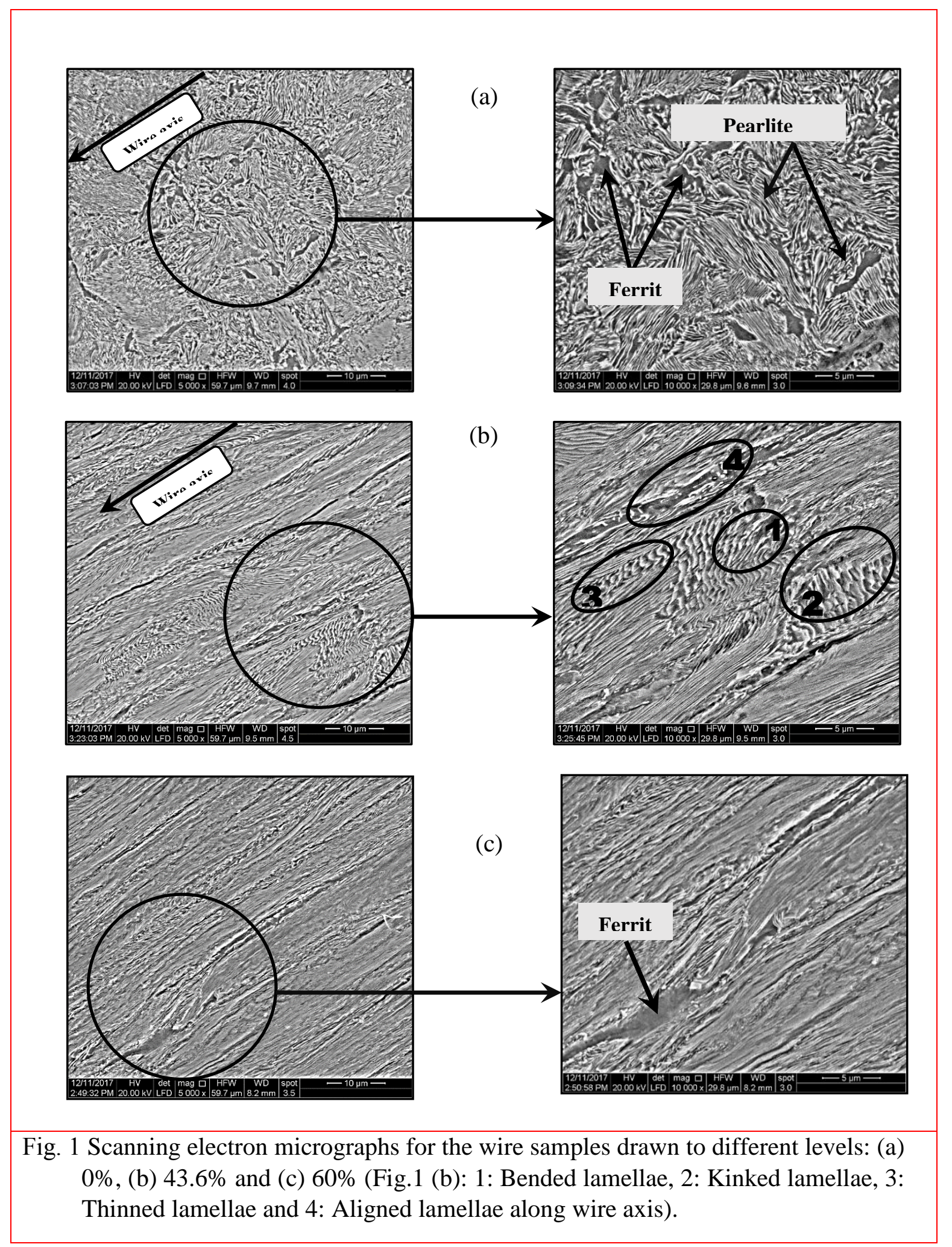




\subsection{Evolution of texture}

It is well known that cold drawn wire has a strong fiber texture $<110>$ of ferrite matrix [10, 11].Figure 2 shows the $\{110\}$ pole figures of steel wires with different deformation levels. An approximately random texture has been seen in wire rod (Fig.3. (a)).

According to the figure 3 , a reinforcement of the intensity of the texture $\langle 110\rangle$ with the increase of the deformation level where the maxima of the pole intensities increases and to reach a value of 6.6 for $60 \%$ deformation level.
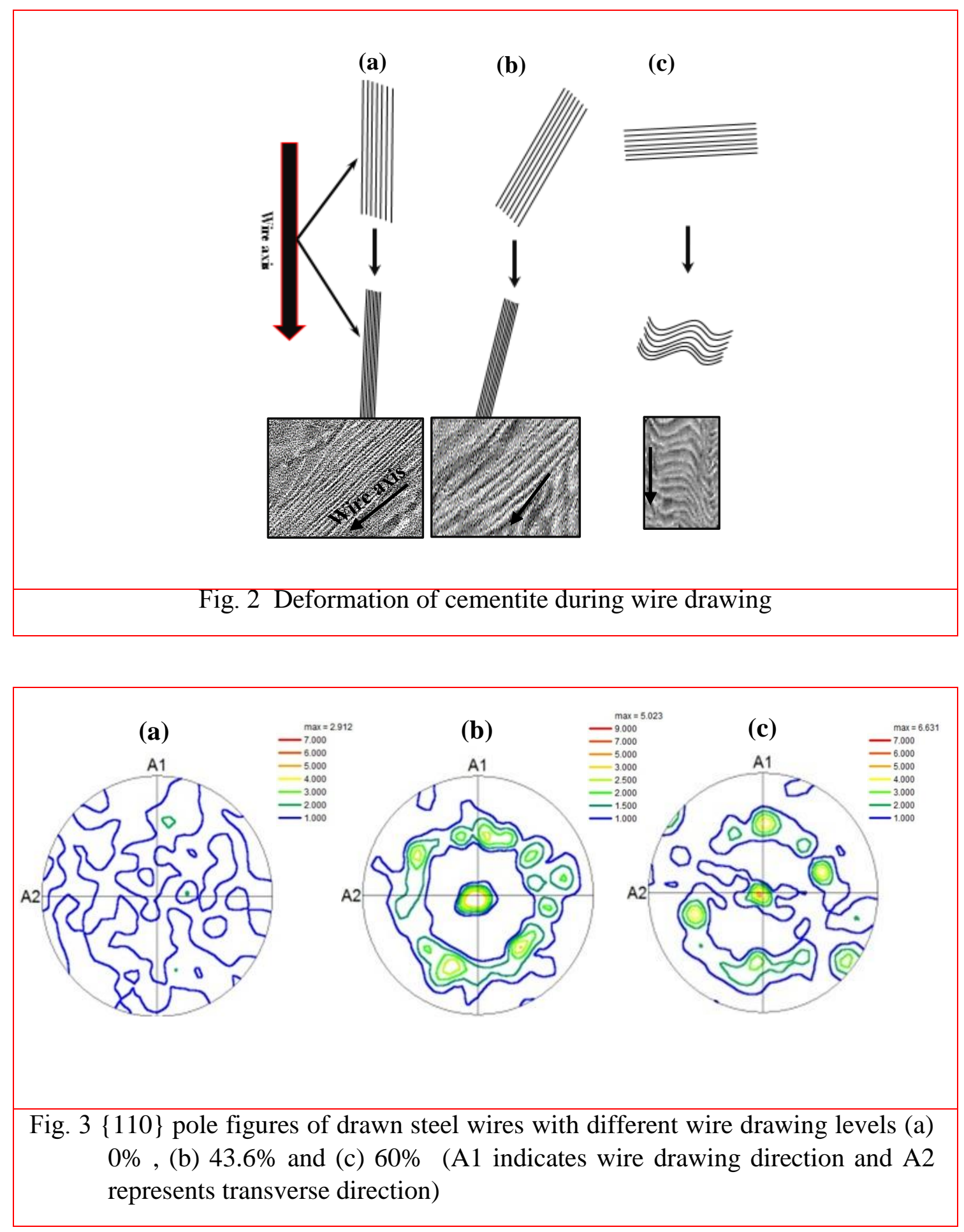


\subsection{X-ray diffraction}

The characterization of the phases is carried out by X-ray diffraction. Figure 4 reveals only the peaks relating to the ferrite $(\alpha-\mathrm{Fe})$. The absence of a cementite peak confirms the data from the literature, where the carbide phase in the steel is identifiable by XRD in the case of there are five or more.

After deformation, the $\alpha$-Fe (110), $\alpha$-Fe (200) and $\alpha$-Fe (211) peaks intensities decrease when the deformation level increases. The comparison between Fig. 4 a, b and c shows that the diffraction peaks of the ferritic phase are shifted to the higher diffraction angle after deformation. This shift corresponds to a modification in to lattice parameters and defects in stacking during wire drawing or to an increase with the amount of interstitial carbon atoms in the bcc structure [12].

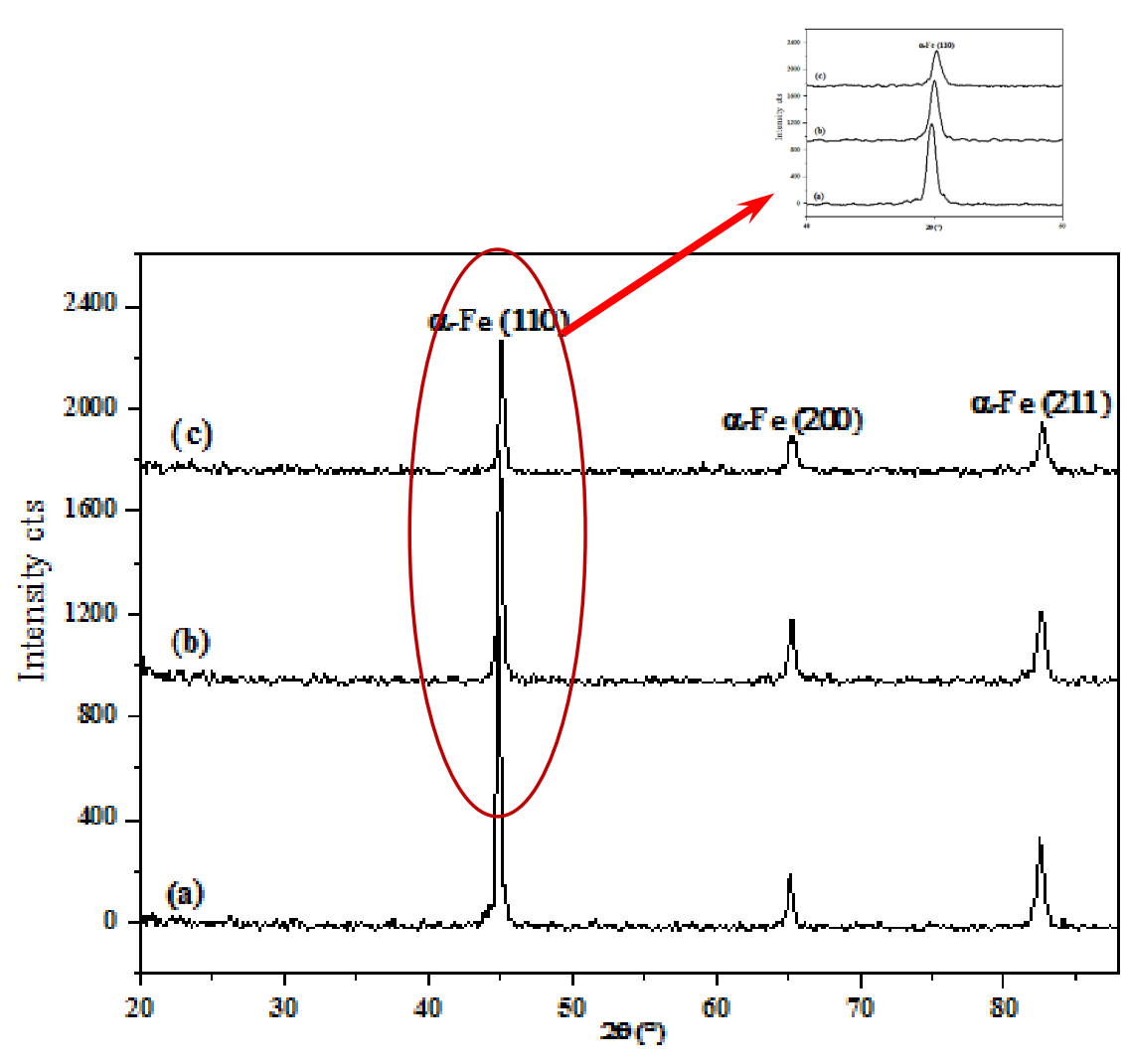

Fig. 4 X-ray diffractograms recorded at room temperature of drawn medium steel wire with different deformation levels (a) $0 \%$, (b) $43.6 \%$ and (c) $60 \%$.

\subsection{Mechanical properties}

In order to establish the correlation between the deformation level by wire drawing process and the mechanical properties of the wires, mechanical tests were carried out. 


\begin{tabular}{|c|c|c|c|}
\hline \multirow[b]{2}{*}{ Mechanical properties } & \multicolumn{3}{|c|}{ Deformation level } \\
\hline & $\begin{array}{c}\text { Wire rod } \\
(\varepsilon=0 \%)\end{array}$ & $\begin{array}{c}\varepsilon_{1}= \\
43.6 \%\end{array}$ & $\varepsilon_{2}=60 \%$ \\
\hline Hardness (HV) 500 g & 295 & 350 & 430 \\
\hline Tensile Strength Rm (Mpa) & 999.3 & 1646.5 & 1753.4 \\
\hline Elongation $\mathbf{E}(\%)$ & 20.9 & 7.6 & 3.3 \\
\hline
\end{tabular}

Figure 5 shows the effect of wire drawing level on the hardness, tensile strength and elongation of drawn medium carbon steel.

In the figure 5 (a) we can observe that wire drawing process causes a hardening of wires. This hardening is due to the generation of additional dislocations within steel structure and hardening of pearlite by the refining of interlamellar spacing during wire drawing [13, 14].Figures 5 ( $b$ and $c$ ) show that tensile strength increases with the deformation level while elongation decreases significantly. Before drawing, the wire rod has a tensile strength of around 999.3 MPa. The tensile strength of drawn medium steel wire achieved 1646.5 MPa and $1753.4 \mathrm{MPa}$ for $43.6 \%$ and $60 \%$ deformation levels, respectively. The wire drawing improve hardening rate of medium steel wire.

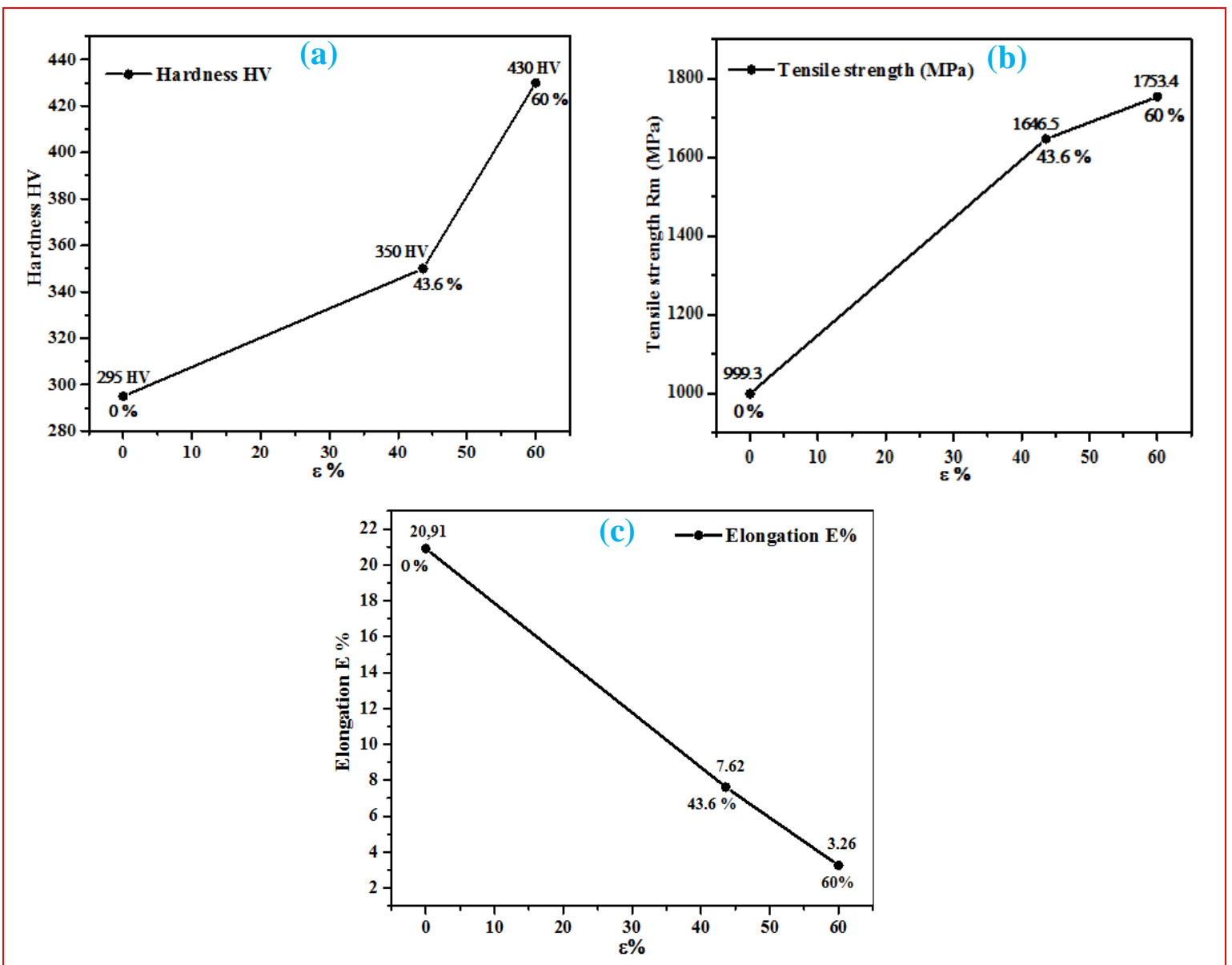

Fig. 5 Mechanical properties of drawn steel wires (a) hardness Vickers, (b) Tensile strength and (c) Elongation 


\section{Conclusion}

Evolutions of microstructure, texture and mechanical properties in medium carbon steel during wire drawing have been investigated.On the basis of the experimental results obtained we can conclude that:

-Wire drawing of medium carbon steel is characterized by microstructural evolution for cementite and ferrite phase with evolution of pearlite colonies. Before wire drawing the pearlite colonies are distributed in an irregular way. After wire drawing the pearlitic colonies and the cementite lamellae were oriented gradually in the direction of deformation. Four forms of cementite lamellae present in the microstructure drawn wire at $43.6 \%$ which are the bended, kinked, thinned and aligned cementite lamellae along wire axis.

-The fiber texture $<110>/ / \mathrm{WA}$ of the ferritic matrix begins to forms after deformation and develops with deformation level by wire drawing.

-Wire drawing causes changes to the crystalline parameters. These changes are due to the increase in stacking defects such as the density of the dislocations.

- Wire drawing increases the tensile strength, decreases the elongation and hardens the medium carbon steel wires.

\section{References}

[1] A. Phelippeau, S .Pommier, T.Tsakalakos, M. Clavel, C.Prioul., 'Cold drawn steel wiresprocessing, residual stresses and ductility-part I: metallography and finite element analyses', Fatigue and Fracture of Engineering Materials and Structures 29 (3) (2006) $201-207$

[2] L. Zhou, Y. Zhao, F.Fang, 'Effect of reserved texture on mechanical properties of cold drawn pearlitic steel wire', Advanced Materials Research 936(2014) 1948-1952

[3] N. Guo, Q. Liu, Y.C. Xin, B.F.Luan, Z. Zhou, 'The application of back-scattered electron imaging for characterization of pearlitic steels', Science China Technological Sciences 54(2011) 2368-2372

[4] J. Toribio and A.M .lancha, 'Effect of cold drawing on environmentally assisted cracking of cold-drawn steel', Journal of Materials Science 31 (1996) 6015-6024

[5] J.Toribio and E. Ovejero, 'Microstructure orientation in a pearlitic steel subjected to progressive plastic deformation', Journal of Materials Science Letters 17(1998) 1037-1040

[6] J.D.Embury and R.M Fisher, 'The structure and properties of drawn pearlite', ActaMetallurgica14(1966) 147-159

[7] Y.J.Li, P.Choi, S.Goto, C.Borchers, D.B.Raabe, R.Kirchheim, 'Evolution of strength and microstructure during annealing of heavily cold-drawn $6.3 \mathrm{GPa}$ hypereutectoid pearlitic steel wire', ActaMaterialia 60(2012) 4005-4016

[8] P.Kumar, N.P.Gurao, A.Haldar, S.Suwas, 'Progressive changes in the microstructure and texture in pearlitic steel during wire drawing', ISIJ International 51 (2011) 679-684 
[9] W.J.Nam, C.M.Bae, C.S.Lee, 'Effect of carbon content on the Hall-Petch parameter in cold drawn pearlitic steel wires', Journal of materials science 37 (2002) 2243-2249

[10] N.Guo, B.Song, B.S.Wang, Q.Liu, 'Influence of torsion deformation on textures of cold drawing pearlitic steel wires', ActaMetallurgicaSinica 28 (2015) 707-714

[11] F.Yang, C.Ma, J.Q.Jiang, H.P.Feng, S.Y.Zhai, 'Effect of cumulative strain on texture characteristics during wire drawing of eutectoid steels', ScriptaMaterialia 59(2000) 850853

[12] S.Tagashira, K.Sakai, T.Furuhara, T.Maki, 'Deformation microstructure and tensile strength of cold rolled pearlitic steel sheets', ISIJ International4 (2000)1149-1155

[13] C.C.Robert, B.Forfert, B.bolle, J.J.Fundenberger, A.Tidu, 'Influence of torsion deformation on microstructure of cold-drawn pearlitic steel wire', Journal of Materials Science 43(2008) 1241-1248

[14] N.A.Raji and O.O.Oluwole, 'Mechanical properties of cold-drawn low carbon steel for nail manufacture: experimental observation', Research Journal of Applied Sciences, Engineering and Technology 5 (2013) 118-122 